\title{
Anthropogenic noise compromises anti-predator behaviour in European eels
}

\author{
Stephen D. Simpson ${ }^{1 *}$, Julia Purser ${ }^{2} \&$ Andrew N. Radford ${ }^{2}$
}

${ }_{1}$ Biosciences, College of Life and Environmental Sciences, University of Exeter, Exeter, EX4 4QD, United Kingdom

${ }^{2}$ School of Biological Sciences \& Cabot Institute, University of Bristol, Woodland Road, Bristol, BS8 $1 U G$, United Kingdom

*Corresponding author, email: S.Simpson@exeter.ac.uk, telephone: +44 1392722714

\section{Running title: Noise compromises anti-predator behaviour}

Keywords: Noise pollution, global change, fitness consequences, survival, shipping Article type: Primary Research Article

\begin{abstract}
Increases in noise-generating human activities since the Industrial Revolution have changed the acoustic landscape of many terrestrial and aquatic ecosystems. Anthropogenic noise is now recognised as a major pollutant of international concern, and recent studies have demonstrated impacts on, for instance, hearing thresholds, communication, movement and foraging in a range of species. However, consequences for survival and reproductive success are difficult to ascertain. Using a series of laboratory-based experiments and an open-water test with the same methodology, we show that acoustic disturbance can compromise anti-predator behaviour - which directly affects survival likelihood - and explore potential underlying mechanisms. Juvenile European eels (Anguilla anguilla) exposed to additional noise (playback of recordings of ships passing through harbours), rather than control conditions (playback of recordings from the same harbours without ships), performed less well in two simulated predation paradigms. Eels were 50\% less likely and 25\% slower to startle to an "ambush predator" and were caught more than twice as quickly by a "pursuit predator". Furthermore, eels experiencing additional noise had
\end{abstract}


diminished spatial performance and elevated ventilation and metabolic rates (indicators of stress) compared with control individuals. Our results suggest that acoustic disturbance could have important physiological and behavioural impacts on animals, compromising life-or-death responses.

\section{Introduction}

Noise-generating human activities in aquatic environments, such as commercial shipping, recreational boating, pile-driving, seismic exploration and energy production, are widespread and occur with increasing frequency (McDonald et al., 2006; Normandeau Associates, 2012). In terrestrial environments, the prevalence of transportation networks, resource extraction and urban development, for example, is similarly greater now than ever before (Watts et al., 2007; Barber et al., 2009). In addition to increasing the amount of noise, human activities often generate sounds that are very different from those arising from natural sources (Hildebrand, 2009; Popper \& Hastings, 2009; Normandeau Associates, 2012). Consequently, anthropogenic (man-made) noise has changed the acoustic landscape of many areas around the globe and represents a very real, and often novel, challenge to animals. It is therefore recognised as a major component of environmental change and a pollutant of international concern; for example, anthropogenic noise is included in the US National Environment Policy Act and the European Commission Marine Strategy Framework Directive, and as a permanent item on the International Maritime Organisation Marine Environmental Protection Committee agenda.

Recent studies on a wide variety of taxa have demonstrated impacts of anthropogenic noise across a range of scales, from individual organisms to community ecology (see reviews in Tyack, 2008; Barber et al., 2009; Slabbekoorn et al., 2010; Normandeau Associates, 2012; Morley et al., 2014). At an individual level, the most dramatic effects are injury or even death experienced by some, but not all, species when very close to certain, particularly impulsive, sound sources (Keevin \& Hempen, 1997; Halvorsen et al., 2012). Further from the source, there may be physiological effects, including temporary threshold shifts (transient reductions in hearing sensitivity) and stress, although again this has been found in only some of the species tested (e.g. Popper et al., 2005, 2007; Wysocki et al., 2006, 2007). Furthest from the source, behavioural effects are the most likely to occur, and thus it is behavioural changes that represent the most widespread impact of anthropogenic noise (Normandeau Associates, 2012). 
Elevated or changed sound levels could affect animal behaviour in three main ways, which are not mutually exclusive. Noise could act as a stressor (Wright et al., 2007; Kight \& Swaddle, 2011), could act as a distracting stimulus, diverting an individual's limited amount of attention from their primary tasks (Mendl, 1999; Chan \& Blumstein, 2011), or could mask crucial acoustic cues or signals (Brumm \& Slabbekoorn, 2005; Radford et al., 2014a). Numerous studies have considered how anthropogenic noise consequently affects communication, movement patterns and foraging (Barber et al., 2009; Slabbekoorn et al., 2010; Radford et al., 2014a). However, it is often difficult to translate these effects into meaningful predictions about individual fitness and population-level consequences (NRC, 2005; Morley et al., 2014), because animals may be able to move away from the source, disturbances may be sporadic and compensation may prevent long-term impacts (NRC, 2005; Bejder et al., 2006; Normandeau Associates, 2012). In contrast, studying anti-predator behaviour offers a direct link to individual fitness: a reduced likelihood of escape affects survival and there is no way to compensate for capture by a predator.

Our knowledge of the natural world is the product of a complementary suite of scientific approaches conducted both in captive and field conditions. To explore the impacts of a range of other environmental stressors (e.g. global warming and ocean acidification), a valuable starting point has been to test for specific effects in carefully controlled laboratory conditions (e.g. Dixson et al., 2010; Scott \& Johnston, 2012). This allows the tight control of potentially confounding factors, but accepts the compromise that the "stressor experience" does not fully recreate real-world conditions (Slabbekoorn, 2014). Here we use a series of controlled laboratory-based experiments and an open-water test with the same methodology to investigate the potential for acoustic disturbance to compromise anti-predator behaviour, a topic which has received little empirical attention, and to explore possible underlying mechanisms. We use a well established laboratory model species, the European eel (Anguilla anguilla), which is known to detect frequencies below $300 \mathrm{~Hz}$ (Jerkø et al., 1989), overlapping with the dominant frequencies of ship noise (Normandeau Associates, 2012). In the wild, juvenile eels pass through the busy shipping channels of Western Europe when moving from the deep ocean to rivers (Schweid, 2009). During this transition, they encounter two main types of predation threat: ambush predation when seeking refuge in benthic habitat and pursuit predation in open water. Thus eels make a valuable model system for studying impacts of noise on anti-predator behaviour. 
Specifically, we studied whether the behaviour and physiology of juvenile eels is affected by additional noise (playback of recordings of a ship passing through a harbour) compared with control conditions (playback of recordings from the same harbours without ship noise). We tested the prediction that additional noise would result in eels exhibiting diminished or maladapted responses to predatory threats in ambush and pursuit paradigms. A number of mechanisms may underpin the demonstrated changes in anti-predator responses when eels are exposed to playback of additional noise (Kight \& Swaddle, 2011). So, we then measured spatial and physiological performance, specifically testing for compromised lateralised behaviour and altered metabolic and ventilations rates as indicators of stress.

\section{Material and methods}

\section{Study species and holding conditions}

Glass-stage European eels, collected in the River Severn in May 2011, were reared and weaned onto a commercial diet (Perle eel food, Skretting, Norway) by Glass Eels Ltd., Gloucestershire before transfer to the University of Bristol aquarium facilities. All experiments were conducted using this stock population during July-September 2011 when eels measured 8-12 cm.

Eels were held in 4501 glass stock tanks and moved into 501 glass holding tanks in the experimental room for a minimum of one week prior to experiments. During experiments, eels were fed once daily; water temperature was $16^{\circ} \mathrm{C} \pm 0.2^{\circ} \mathrm{C}$; lighting was provided $13: 11$ day:night; tanks contained artificial plants and tube shelters; filtration was by twice-weekly water changes and water movement was maintained by slow-bubbling airstones to avoid unnecessary noise. Ambient sounds in the stock and holding tanks were recorded using an omnidirectional hydrophone (HTI-96-MIN with inbuilt preamplifier, High Tech Inc., Gulfport MS; manufacturer-calibrated sensitivity $-164.3 \mathrm{~dB}$ re $1 \mathrm{~V} / \mu \mathrm{Pa}$; frequency range 0.2-30 kHz) and an Edirol R09HR 24-Bit recorder (44.1 kHz sampling rate, Roland Corporation, Bellingham WA; recording level calibrated using pure sine wave signals from a function generator with a measured voltage recorded in line on an oscilloscope). Stock and holding tank recordings were made $2 \mathrm{~cm}$ above the tank floor, at the end of the large long-term stock tank where the eels typically rested, and in the centre of the smaller holding tanks (Fig. 1). Due to unresolved challenges in measuring particle velocity in small tanks, we assessed acoustic conditions in the pressure domain 
only. Although eels are sensitive to particle velocity as well as pressure (Jerkø et al., 1989), in this study we do not attempt to establish absolute values for sensitivity, but rather explore impacts of additional noise on behaviour and physiology (see Rogers 2014 for an excellent examination of the complex pressure and particle velocity conditions in tanks).

\section{Playback tracks}

The 2-min playback tracks used in all the experiments were created using Audacity 1.3.13 (http://audacity.sourceforge.net/) from recordings made at three major UK harbours (as per Wale et al., 2013a,b). Field recordings were made of both ambient harbour noise and ship noise generated by a single passing ship at ca. 100-400 m distance (Gravesend: Rio de la Plata, a $286 \mathrm{~m}$ long, 64,730 t container ship; Plymouth: Bro Distributor, a 147 m long, 14,500 t LPG tanker; Portsmouth: Commodore Goodwill, a $126 \mathrm{~m}$ long, 5,215 t ferry). Ships were travelling at constant, relatively slow speeds ( $<10$ knots), as enforced by port authorities for vessels entering and leaving estuarine areas. Weather conditions during recordings ranged from 0 to 1 on the Douglas Scale of sea state, with a still to moderate wind speed. Recordings were made using the same hydrophone, positioned at $1 \mathrm{~m}$ depth 20-40 $\mathrm{m}$ offshore, and solidstate recorder as described above (see Fig. 1 for spectral analyses).

Sound levels of the three different ambient-harbour (control treatment) and ship-noise (additionalnoise treatment) playback tracks were adjusted to produce equal RMS intensity in the pressure domain to the field recordings when played back using an UW-30 underwater speaker (max output level $153 \mathrm{~dB}$ re 1 $\mu \mathrm{Pa}$ at $1 \mathrm{~m}$, frequency response 0.1 to $10 \mathrm{kHz}$, Lubell Labs Inc., Columbus $\mathrm{OH}$ ). Recordings in test tanks were made $2 \mathrm{~cm}$ above the tank floor, in the centre of the tank for the predation/lateralisation tanks, and $10 \mathrm{~cm}$ from the speaker wall (where fish were placed) for the ventilation/metabolic rate tank (Fig. 1). The three control playback tracks were modified (uniform amplification or attenuation) to play at $\sim 108 \mathrm{~dB}$ RMS re $1 \mathrm{mPa}(106.8,108.6,107.5)$ at the position of the fish (or in the centre of the tank for the pursuit and lateralisation experiment), which was substantially greater than the noise floor in the tanks (96 dB RMS re $1 \mathrm{mPa}$ ), while additional-noise playback tracks were modified to play at $\sim 148 \mathrm{~dB}$ RMS re $1 \mathrm{mPa}$ $(149.0,148.6,147.8)$. 


\section{General experimental design}

Our interest was in the effect of additional noise on behaviour and physiology relative to that exhibited by individuals from the same cohort from the same holding conditions that experienced control playbacks; any treatment-based effect is not the consequence of captive conditions per se. In each experiment, individual eels were tested once in an independent-samples design. All experiments (except the assessment of metabolic rate) involved an initial period of a control playback from one of the three harbours $(\mathrm{C} 1, \mathrm{C} 2, \mathrm{C} 3)$, followed by a switch to playback of either a control recording or an additionalnoise recording $(\mathrm{N} 1, \mathrm{~N} 2, \mathrm{~N} 3)$ from a different harbour. As such, there were 12 possible combinations of control to control or control to additional-noise playback: $\mathrm{C} 1-\mathrm{C} 2, \mathrm{C} 1-\mathrm{C} 3, \mathrm{C} 1-\mathrm{N} 2, \mathrm{C} 1-\mathrm{N} 3, \mathrm{C} 2-\mathrm{C} 1, \mathrm{C} 2-$ $\mathrm{C} 3, \mathrm{C} 2-\mathrm{N} 1, \mathrm{C} 2-\mathrm{N} 3, \mathrm{C} 3-\mathrm{C} 1, \mathrm{C} 3-\mathrm{C} 2, \mathrm{C} 3-\mathrm{N} 1$ and $\mathrm{C} 3-\mathrm{N} 2$. Testing blocks therefore utilised 12 eels, each one receiving one of the 12 possible playback combinations. The order in which these playback combinations were presented was randomised within each testing block; subsequent analysis confirmed that this did not result in any chance bias in the ordering of control and additional-noise treatments (Mann Whitney $U$ tests on ranked orders: all $P>0.670)$. For the assessment of active metabolic rate, eels experienced only one playback track $(\mathrm{C} 1, \mathrm{C} 2, \mathrm{C} 3, \mathrm{~N} 1, \mathrm{~N} 2$ or $\mathrm{N} 3)$, and thus testing blocks utilised six eels which each received one track in randomised order. Subsequent analysis again confirmed that there was no chance bias in the ordering of control and additional-noise treatments $(P=0.934)$. The lack of an order bias within blocks rules out the possibility that an unmeasured potential confounding effect, such as an accumulation of stress hormones in the water, could explain any treatment-based differences found.

All datasets were analysed using two-way ANOVAs to assess the impact of acoustic treatment (control or additional-noise), while controlling for any potential effect of testing block (which was never significant, all $P>0.159$ ); the interaction term was never significant (all $P>0.120$ ). The non-significant effect of block indicates that there were no changes across time in, for example, the ability of the catcher in the pursuit predation paradigm.

\section{Predation experiments}

Predation experiments were conducted under UK Home Office licensing (PPL 30/2860) in a 120 x $40 \mathrm{~cm}$ (water depth: $40 \mathrm{~cm}$; wall thickness: $4 \mathrm{~mm}$ ) glass tank, with an upward-facing loudspeaker suspended 
underneath a false $4 \mathrm{~mm}$ thick Perspex bottom. The experiment considering an ambush (sit-wait-strike) predatory threat used the well-established looming stimulus approach, which isolates the visual component of a predatory strike; this method has been used to assess fish anti-predator responses in a range of research fields (Batty, 1989; Fuiman \& Cowan, 2003). A model fish on a swinging pendulum arm, which moved through $45^{\circ}$ to a position next to the glass, was placed beyond one end of the tank. The tank was illuminated from above and the observer was behind a screen. An eel from a holding tank was caught in a transfer jug and left for 2 min to settle; during this time, all eels returned to a normal sedentary mode. A control playback track was switched on in the experimental tank (by A.N.R., who operated the sound system throughout) and the eel released into the end furthest from the model fish. After 1 min acclimatisation, when eels freely explored the tank, the track was switched to either another control track or an additional-noise track. When the eel first passed the 'predator window' (a $20 \mathrm{~cm}$ wide stretch of glass in front of the predator), the predator was remotelyreleased by S.D.S., who was listening to loud music through headphones and so was unaware of the acoustic treatment in the tank. Eels in the two playback treatments did not differ significantly in the time until they first passed the predator window (ANOVA: $\left.\mathrm{F}_{1,43}=0.07, \mathrm{p}=0.800\right)$. The entire trial, including any responses to the looming predatory stimulus, was recorded on video (Casio EX-FH20, Tokyo, Japan) for later analysis. S.D.S. scored the videos without sound (and thus 'blind' to the acoustic treatment), to determine whether the eel startled (exhibit a directional change in swimming trajectory between consecutive frames) and, if it did, the time taken to startle (from initiation of model release). The occurrence of a startle reaction indicates detection and response to a stimulus as a potential threat, and is the first stage in a typical defence cascade (Cacioppo et al., 2000). The water in the experimental tank was stirred between trials to homogenise any olfactory cues, and we tested 48 eels in four blocks, changing the water between each block.

To consider how additional noise affects the response to a pursuit (chase and catch) predatory threat, eels were chased through a maze with a handnet until captured. The maze was created in the experimental tank by the addition of two static $70 \mathrm{~cm}$ "[" shaped Perspex baffles in a staggered formation. Transfer and settling of eels, and initiation of playbacks, was the same as for the ambush predator experiment (above). When the track was switched, catching was initiated from the far end of the tank from the current position of the eel. The catcher (always S.D.S.) could only chase the eel (no ambush 
tactics were allowed); he was 'blind' to the acoustic treatment throughout (see above); and operated from a fixed position at the side of the tank wearing the same external clothing during all blocks. We compared the time taken to catch each eel depending on whether a control or additional-noise track was playing in the tank. The water in the experimental tank was stirred between trials to homogenise any olfactory cues, and we tested 60 eels in five blocks, changing the water between each block.

\section{Potential underlying mechanisms}

To assess the impact of additional noise on characteristic spatial behaviour, we assessed the degree of lateralisation displayed in both noise treatments, using the standard measure of the proportion of turns in a preferred direction at symmetrical junctions in a maze (Domenici et al., 2012). Lateralised behaviour is important in fishes for predator inspection, spatial cognition and schooling (Brown et al., 2004;

Braithwaite, 2006). We used the same tank as in the predation experiments, with the same Perspex baffles positioned in parallel to create a simple "][" maze with a central corridor and T-junction at each end. The tank was illuminated centrally from above, a ceiling-mounted mirror was used to give an aerial view for monitoring eel behaviour, and the observer was behind a screen to remain hidden from the eel even in the mirror. For each trial, an eel from a holding tank was caught in a transfer jug and left to settle for 2 min. A control track was then switched on in the experimental tank and the eel transferred to one end of the maze. The eel was given 5 min to explore the arena and then the direction of the next 10 turns made by the eel (five at each end) was recorded; at no stage did eels need tobe guided into the maze during the experiments. Playback was then switched to another control track or an additional-noise track and the direction of the subsequent 10 turns recorded to assess any change in directional preference exhibited. The water in the experimental tank was stirred between trials to homogenise any olfactory cues and changed after each block of 12 eels; 48 eels were tested in total.

To explore whether the changes in anti-predator behaviour are potentially underpinned by physiological state, we considered two standard measures that are commonly used as indicators of stress: ventilation (opercular beat rate) and active metabolic rate (oxygen usage) (Barton, 2002). For opercular beat rate, individual eels were placed into $30 \mathrm{ml}$ gas-tight sealed tubes (polystyrene $1 \mathrm{~mm}$ wall thickness; estimated to be $90-95 \%$ acoustically transparent based on typical acoustic impedance of polystyrene vs. 
water) inside the test tank at a fixed location $10 \mathrm{~cm}$ from the speaker. The plastic test tank was 34 x 20 cm (water depth: $16 \mathrm{~cm}$; wall thickness: $2 \mathrm{~mm}$ ), with a sideward-facing loudspeaker suspended at one end. Eels were allowed to settle for 2 min while a control track was playing. An observer (always S.D.S.), 'blind' to the acoustic treatment (see above), then counted opercular beats for $1 \mathrm{~min}$. If opercular beat could not be observed, counting was paused; for every individual tested, a full $1 \mathrm{~min}$ of beats was counted (always within $90 \mathrm{~s}$ ). The track was then switched to another control track or an additional-noise track, and 1 min of opercular beats was counted as before. Time was monitored and the track was switched by a second observer (A.N.R.). The water in the tubes was replaced with fully-aerated water after each eel and we tested 24 individuals in two blocks.

To determine oxygen usage in both the laboratory and an open-water study, individual eels were placed in the same tubes as used for the measurement of opercular beat rate, with the tops sealed underwater to avoid air bubbles. After an eel was placed in a tube, the playback track was randomly selected to avoid any biases arising from preferential capture. Dissolved oxygen content of the water at the start of each trial was tested (Morris et al., 2005) (laboratory study: Dissolved Oxygen Meter 781, Strathkelvin Instruments, SI Ltd., North Lanarkshire, UK; open-water study: Dissolved Oxygen and Temperature Meter HI 9164, Hanna Instruments Inc., USA). Sealed tubes were placed $10 \mathrm{~cm}$ from a speaker, either in a test tank (laboratory study) or in a mesh tray suspended $20 \mathrm{~cm}$ below the surface (total

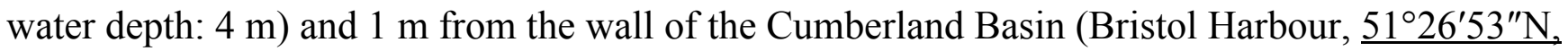

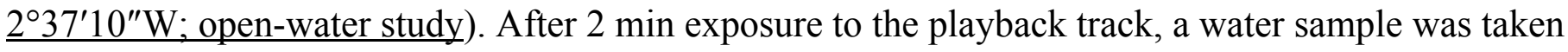
from the tube and the dissolved oxygen content tested. In each experiment, we tested 48 eels in four blocks and analysis was conducted on the percentage change in dissolved oxygen content (to account for minor variation in the starting value).

\section{Results}

\section{Predation experiments}

In the experiment considering an ambush predatory threat, individuals exposed to additional noise at the time of "attack" were 50\% less likely to startle than those attacked during the control treatment (chisquared test: $\chi^{2}{ }_{1}=8.57, \mathrm{n}=48, P=0.003$; Fig. 2a). Moreover, individuals that did startle during 
additional-noise playback were $25 \%$ slower to do so than those that startled in the control treatment (ANOVA: $F_{1,23}=10.26, P=0.004$; Fig. $2 \mathrm{~b}$ ). The startle response is crucial for prey to survive attacks by ambush predators and, if successful, is likely to terminate the predator-prey interaction as the predator returns to its ambush position.

In the experiment considering a pursuit predation threat, eels experiencing additional noise were caught more than twice as quickly as those in the control treatment (ANOVA: $F_{1,54}=10.78, P=0.002$; Fig. 2c). In the wild, the probability of successful escape is likely to increase the longer that capture can be avoided, either because the prey may find a suitable shelter to hide or because the predator gives up the chase as energetically too costly.

\section{Potential underlying mechanisms}

The initial high level of lateralisation (proportion of turns in a preferred direction) apparent during playback of a control track was unchanged with a switch to a different control track (Fig. 3a), but declined with a switch to additional-noise playback (Fig. 3b); there was a significant loss in directional bias with additional noise (ANOVA: $F_{1,43}=40.24, P<0.001$; Fig. $3 \mathrm{c}$ ). In the context of our pursuit predation paradigm, lateralisation may be important for rapid decision-making and optimal utilisation of a spatially complex environment when attempting to reduce the likelihood of capture.

There was no significant change in opercular beat rate when one control track was exchanged for another, but eels exhibited a significant increase in opercular beat rate when a control track was replaced with an additional-noise track (ANOVA, change in beat rate between periods: $F_{1,21}=21.80, P<0.001$; Fig. 3d). In the laboratory-based assessment of active metabolic rate, eels exposed to playback of additional noise showed a significant increase in oxygen usage compared to those in the control treatment $\left(F_{1,43}=13.77, P=0.001\right.$; Fig. 3e $)$; there was no noticeable difference in movement (almost all individuals in both treatments remained stationary during playback). The same treatment-related difference in active metabolic rate was found in the open-water test: eels used significantly more oxygen during additional-noise playback than during control playback $\left(F_{1,43}=49.82, P<0.001\right)$. 


\section{Discussion}

We found that acoustic disturbance detrimentally affects anti-predator performance of juvenile eels in experimental ambush and pursuit predation paradigms. The influence of noise on anti-predator behaviour has received little research attention (two previous studies indicated that crabs were less likely to detect a looming stimulus; Chan et al., 2010; Wale et al., 2013a), but we suggest that information on such direct determinants of survival is particularly valuable. Further investigation is needed to test the extent to which acoustic disturbance may also affect predators, and to determine the interactive effect on the performance of both parties during predation events.

In addition to effects on anti-predator behaviour, we also provide evidence that acoustic disturbance can cause changes in spatial behaviour and physiological state. Using a standard test of lateralisation, we found that additional-noise playback caused a reduction in characteristic lateralised behaviour in eels. Since lateralised behaviour in fish is important for spatial cognitive tasks and antipredator behaviour, including predator recognition (Brown et al., 2004; Braithwaite, 2006), the observed loss of lateralisation may have compromised optimal space use by eels in the pursuit predation experiment, hence reducing time to capture. A study demonstrating impacts of ocean acidification on lateralisation suggests that brain function may be more fundamentally affected by elevated $\mathrm{CO}_{2}$ conditions (Domenici et al., 2012). Whether noise also influences brain function at a more fundamental level remains to be tested.

The noise-induced alteration in physiological state could indicate a more general allostatic stress response, with the intensity, duration and frequency of multiple aspects of behaviours likely to be affected (Broom \& Johnson, 1993; McEwan \& Wingfield, 2003; Wingfield, 2005); a previous study measuring cortisol levels in fish has also suggested that noise is a stressor (Wysocki et al., 2006, but see Wysocki et al., 2007). If this response includes a reduction or cessation of normal locomotor activity (Metcalfe et al., 1987), for example, then the likelihood of escape from a predator may be reduced. An allostatic stress response could also potentially affect attention (Chan \& Blumstein, 2011), as would noise acting as a distractor (Chan et al., 2010), compromising anti-predator behaviour that relies on cognitive processes including detection, classification and decision-making (Mendl, 1999; Shettleworth, 2010). Furthermore, the addition of noise may have masked (Brumm \& Slabbekoorn, 2005) the noise of the 
handnet in the pursuit predation experiment, but not the visual or tactile cues; masking is unlikely as an explanation in the looming stimulus experiment where the "predator" was not coupled to the tank.

Playback of field recordings are known to be qualitatively different from the original noise source and acoustic conditions in small tanks are complex (Parvulescu, 1967; Okumura et al., 2002). However, our primary aim was to investigate whether acoustic disturbance, rather than a particular noise source, has the potential to have an impact. Our finding of a similar alteration in active metabolic rate using the same methods in a tank and in open water also suggests that the demonstrated impacts are not simply an artefact of the reflections and reverberations that occur in tank environments. From a biological perspective, captive animals are usually more constrained than in the wild, and individuals receive husbandry regimes that do not fully replicate natural conditions of resource availability. However, experiments in tanks allow tight control of conditions and contexts, as well as detailed data collection, and have proved a valuable stepping stone in the study of other environmental stressors (Dixson et al., 2010; Scott \& Johnston, 2012). Our experiments show that near to the sound source there are impacts of acoustic disturbance with implications for survival, while sonar-based tracking of free-swimming fish indicates changes in swimming behaviour near to vessels (Handegard et al., 2003; Hawkins et al., 2014). Ultimately, studies in open-water conditions are needed to investigate the spatial scale of impacts that carry fitness consequences.

There is clearly further potential for scientific exploration in carefully controlled conditions of how acousticdisturbance affects animals, for example considering intra-population variation, contextdependency, prior experience and recovery (Radford et al., 2014b), and testing whether frequent or continuous exposure to noise may lead to changes in response due to tolerance, habituation or sensitisation (Bejder et al., 2009; Wale et al., 2013b). In an applied context, the main challenge moving forwards is to deliver to regulators evidence that can be directly useful to management and policy decisions, considering dose-dependent responses to real-world anthropogenic noise sources. For now, our laboratory-based findings that additional noise compromises anti-predator and lateralised behaviour and physiological state, with potential survival consequences, suggest that further work on this contemporary global environmental change issue is warranted. 


\section{Acknowledgements}

We thank Sophie Holles and Irene Völlmy for making the original sound recordings, Rick Bruintjes and Kirsty Everley for assistance with the open-water test, the University of Bristol Animal Services Unit for maintaining the eels, the Bristol Port Authority for permission to work in the Cumberland Basin and Dan Fagan for assistance with dissolved oxygen measurements. Our work has benefitted greatly from discussions with Mardi Hastings, Tony Hawkins, Art Popper and Rod Wilson, and the manuscript was improved by comments from Innes Cuthill, Julian Partridge, Nick Roberts and Tim Fawcett. This work was supported by the UK Department for Environment Food and Rural Affairs (Defra; ME5207) and a NERC Knowledge Exchange Fellowship (for S.D.S.; NE/J500616/2). We declare no conflict of interests.

\section{References}

Barber JR, Crooks KR, Fristrup KM (2009) The costs of chronic noise exposure for terrestrial organisms. Trends in Ecology and Evolution, 25, 180-189.

Barton BA (2002) Stress in fishes: A diversity of responses with particular reference to changes in circulating corticosteroids. Integrative and Comparative Biology, 42, 517-525.

Batty RS (1989) Escape responses of herring larvae to visual stimuli. Journal of the Marine Biological Association, 69, 647-654.

Bejder L, Samuels A, Whitehead H, Gales N (2006) Interpreting short-term behavioural responses to disturbance within a longitudinal perspective. Animal Behaviour, 72, 1149-1158.

Bejder L, Samuels A, Whitehead H, Finn H, Allen S (2009) Impact assessment research: use and misuse of habituation, sensitisation and tolerance in describing wildlife responses to anthropogenic stimuli. Marine Ecology Progress Series, 395, 177-185.

Braithwaite VA (2006) Cognitive ability in fish. In: Fish Physiology: Behaviour and Physiology of Fish, Vol. 24 (eds. Sloman KA, Balshine S, Wilson RW) pp. 1-37, Academic Press, London.

Broom DM, Johnson KG (1993) Stress and Animal Welfare. Kluwer, Dordrecht.

Brown C, Gardner C, Braithwaite VA (2004) Population variation in lateralized eye use in the poeciliid Brachyraphis episcopi. Proceedings of the Royal Society of London, Series B, 271, S455-S457.

Brumm H, Slabbekoorn H (2005) Acoustic communication in noise. Advances in the Study of Behavior, 
35, 151-209.

Cacioppo JT, Tassinary LG, Berntson GG (2000) Handbook of Psychophysiology. Cambridge University Press, Cambridge.

Chan AAY-H, Giraldo-Perez P, Smith S, Blumstein DT (2010) Anthropogenic noise affects risk assessment and attention: the distracted prey hypothesis. Biology Letters, 6, 458-461.

Chan AAY-H, Blumstein DT (2011) Attention, noise, and implications for wildlife conservation and management. Applied Animal Behaviour Science, 131, 1-7.

Dixson DL, Munday PL, Jones GP (2010) Ocean acidification disrupts the innate ability of fish to detect predator olfactory cues. Ecology Letters, 13, 68-75.

Domenici P, Allan B, McCormick MI, Munday PL (2012) Elevated carbon dioxide affects behavioural lateralization in a coral reef fish. Biology Letters, 8, 78-81.

Fuiman LA, Cowan JH (2003) Behavior and recruitment success in fish larvae: Repeatability and covariation of survival skills. Ecology, 84, 53-67.

Halvorsen MB, Casper BM, Matthews F, Carlson TJ, Popper AN (2012) Effects of exposure to piledriving sounds on the lake sturgeon, Nile Tilapia and hogchoker. Proceedings of the Royal Society, Series B, 279, 4705-4714.

Handegard NO, Michalsen K, Tjøstheim D (2003) Avoidance behavior in cod, Gadus morhua, to a bottom trawling vessel. Aquatic Living Resources, 16, 265-270.

Hawkins AD, Roberts L, Cheesman S (2014) Responses of free-living coastal pelagic fish to impulsive sounds. Journal of the Acoustical Society of America, 135, 3101-3116.

Hildebrand JA (2009) Anthropogenic and natural sources of ambient noise in the ocean. Marine Ecology Progress Series, 395, 4-20.

Jerkø H, Turunen-Rise I, Enger PS, Sand O (1989) Hearing in the eel (Anguilla anguilla). Journal of Comparative Physiology, Series A, 165, 455-459.

Keevin TM, Hempen GL (1997) The environmental effects of underwater explosions with methods to mitigate impacts. U.S. Army Corps of Engineers, St. Louis District. http://www.denix.osd.mil/nr/upload/underwaterexplosions.pdf

Kight CR, Swaddle JP (2011) How and why environmental noise impacts animals: an integrative, 
mechanistic review. Ecology Letters, 14, 1052-1061.

McDonald MA, Hildebrand JA, Wiggins SM (2006) Increases in deep ocean ambient noise in the Northeast Pacific west of San Nicholas Island, California. Journal of the Acoustical Society of America, 120, 711-718.

McEwen BS, Wingfield JC (2003) The concept of allostasis in biology and biomedicine. Hormones and Behaviour, 43, 2-15.

Mendl M (1999) Performing under pressure: stress and cognitive function. Applied Animal Behaviour Science, 65, 221-244.

Metcalfe NB, Huntingford FA, Thorpe JE (1987) The influence of predation risk on the feeding motiation and foraging strategy of juvenile Atlantic salmon. Animal Behaviour, 35, 901-911.

Morley EL, Jones G, Radford AN (2014) The importance of invertebrates when considering the impacts of anthropogenic noise. Proceedings of the Royal Society of London, Series B, 281, 20132683.

Morris S, van Aardt WJ, Ahern MD (2005) The effect of lead on the metabolic and energetic status of the yabby, Cherax destructor, during environmental hypoxia. Aquatic Toxicology, 75, 16-31.

NRC (2005) Marine Mammal Populations and Ocean Noise: Determining When Noise Causes Biologically Significant Effects. National Research Council of the National Academies, National Academy Press, Washington DC.

Normandeau Associates, Inc. (2012) Effects of noise on fish, fisheries, and invertebrates in the U.S. Atlantic and Arctic from energy industry sound-generating activities. A literature synthesis for the U.S. Dept. of the Interior, Bureau of Ocean Energy Management. Contract \# M11PC00031, 153 pp. Available from: http://www.data.boem.gov/homepg/data_center/other/espis/espismaster.asp?appid=1, last accessed on 30 February 2014.

Okumura T, Akamatsu T, Yan HY (2002) Analyses of small tank acoustics: empirical and theoretical approaches. Bioacoustics, 12, 330-332.

Parvulescu A (1967) The acoustics of small tanks. In: Marine Bioacoustics (ed. Tavolga, W.N.) pp.7-14, Pergamon Press, Oxford.

Popper AN, Smith ME, Cott PA, Hanna BW, MacGillivray AO, Austin ME, Mann DA (2005) Effects of exposure to seismic airgun use on hearing of three fish species. Journal of the Acoustical Society of 
America, 117, 3958-3971.

Popper AN, Halvorsen MB, Kane AS, et al. (2007) The effects of high-intensity, low-frequency active sonar on rainbow trout. Journal of the Acoustical Society of America, 122, 626-635.

Popper AN, Hastings MC (2009) The effects of anthropogenic sources of sound on fishes. Journal of Fish Biology, 75, 455-489.

Radford AN, Kerridge E, Simpson SD (2014a) Acoustic communication in a noisy world: can fish compete with anthropogenic noise? Behavioral Ecology, Online early.

Radford AN, Purser J, Bruintjes R, et al. (2014b) Beyond a simple effect: variable and changing responses to anthropogenic noise. Advances in Experimental Medicine and Biology, In press.

Rogers P (2014) Parvulescu revisited: Small tank acoustics for bio-acousticians. Advances in Experimental Medicine and Biology, In press.

Schweid R (2009) Eel. Reaktion Books, London.

Scott GR, Johnson IA (2012) Temperature during embryonic development has persistent effects on thermal acclimation capacity in zebrafish. Proceedings of theNational Academy of Sciences USA, 109, $14247-14252$.

Shettleworth SJ (2010) Cognition, Evolution, and Behavior. 2nd edn. Oxford University Press, Oxford.

Slabbekoorn H, Bouton N, van Opzeeland I, Coers A, ten Cate C, Popper AN (2010) A noisy spring: the impact of globally rising underwater sound levels on fish. Trends in Ecology and Evolution., 25, 419427.

Slabbekoorn H (2014) Aiming for progress in understanding underwater noise impact on fish: complementary need for indoor and outdoor studies. Advances in Experimental Medicine and Biology, In press.

Tyack P (2008) Implications for marine mammals of large-scale changes in the marine acoustic environment. Journal of Mammalogy, 89, 549-558.

Wale M, Simpson SD, Radford AN (2013a) Noise negatively affects foraging and anti-predator behaviour in shore crabs. Animal Behaviour, 86, 111-118.

Wale M, Simpson SD, Radford AN (2013b) Size-dependent physiological responses of shore crabs to single and repeated playback of ship noise. Biology Letters, 9, 20121194. 
Watts RD, Compton RW, McCammon JH, Rich CL, Wright SM, Owens T, Ouren DS (2007) Roadless space of the conterminous United States. Science, 316, 736-738.

Wingfield JC (2005) The concept of allostasis: coping with a capricious environment. Journal of Mammalogy, 86, 248-254.

Wright AJ, Soto NA, Baldwin AL, et al. (2007) Anthropogenic noise as a stressor in animals: a multidisciplinary perspective. International Journal of Comparative Psychology, 20, 250-273.

Wysocki LE, Dittami JP, Ladich F (2006) Ship noise and cortisol secretion in European freshwater fishes. Biological Conservation, 128, 501-508.

Wysocki LE, Davidson JW, Smith ME, et al. (2007) Effects of aquaculture production noise on hearing, growth, and disease resistance of rainbow trout Oncohynchus mykiss. Aquaculture, 272, 687-697.

\section{Figure legends}

Figure 1 Spectral analyses of field and tank-based recordings. Analyses include baseline conditions in the stock and the holding tanks, original field recordings of ambient harbour noise and ship noise, and control and additional-noise playback tracks in each type of test tank. Fast Fourier Transform (FFT) analysis of sound 50-5000 Hz, using Avisoft SASLabPro v5.2.07 (Avisoft Bioacoustics): spectrum level units normalised to $1 \mathrm{~Hz}$ bandwidth, Hann evaluation window, 50\% overlap, FFT size 1024, averaged from a $15 \mathrm{~s}$ sample of each recording, $43 \mathrm{~Hz}$ intervals presented.

Figure 2 Anti-predator responses of eels during playback of control and additional-noise tracks. (a) Number of eels exhibiting a startle response or not to a looming stimulus $(\mathrm{n}=24$ for each treatment). (b) Mean \pm SE time taken to startle to looming stimulus by those individuals in (a) that exhibited a startle response (control treatment: $\mathrm{n}=19$; additional-noise treatment: $\mathrm{n}=9$ ). (c) Mean \pm SE time to capture free-swimming eels in a maze with a handnet $(n=30$ for each treatment).

Figure 3 Potential underlying mechanisms for the impact of acoustic disturbance on eel anti-predator behaviour. ( $\mathrm{a}$ and b) Lateralisation of eels during initial playback of control tracks ('before') and during subsequent playback ('during') of either another control track (a) or an additional-noise track (b) (n = 24 
in each case). (c) Mean \pm SE change in directional bias exhibited by eels following the switch in playback track $(n=24$ in each case). (d) Mean \pm SE ventilation rate of eels during playback of control or additional-noise tracks. Ventilation was recorded for 1 min while eels were exposed to a control track ('before') and then for a further 1 min after switching the playback ('during') to either an additional-noise track or another control track $(n=12$ in each case). (e) Mean \pm SE oxygen depletion in tubes with eels exposed to playback of control or additional-noise tracks $(n=24$ for each treatment). 